\title{
Място на носните промивки в лечението на заболяванията на носа и околоносните кухини
}

Литературен обзор

\author{
А. Куцаров, д.м. \\ УНГ; МБАЛ „Авис Медика“ гр. Плевен
}

\section{Резюме}

Цел: Да се направи преглед на литературата, относно ефективността на физиологичните разтвори за носни промивки в лечението на сино-назалните болести. Оценката се базира на попълване на въпросници.

Източници на данни: Клинични проучвания публикувани в Medline, Cochrane library и EPOS 2012.

Резултати: Носните промивки се използват често като моно или комбинирана терапия при лечението на синоназалните болести, включително алергичния ринит и хроничния риносинуит. Те водят до намаляване на възпалението и облекчаване на назалните симптоми. Определянето на оптимална техника на приложение на солевите разтвори е затруднена, поради факта, че отделните проучвания използват различни устройства за апликация на разтвора, които демонстрират различни ефекти върху мукоцилиарния клирънс и този на възпалителните медиатори.

Заключение: Като цяло, данните показват клинична полза от носните промивки. Последните се понасят добре и имат минимални странични ефекти. Допълнителни изследвания са необходими, за оптимизиране на ефикасността.

\footnotetext{
Abstract

Objective: This review examines the literature regarding nasal saline irrigation in the management ofsinonasal disease. We explore the various properties of nasal irrigation solutions and their effects on nasal symptoms.

Data Sources: English-language studies identified from MEDLINE, EPOS (2012) and the Cochrane Central Register of Controlled Trials.

Study Selections: Randomized, controlled trials (RCTs), prospective controlled and comparative studies, and observational studies reporting on the indications, efficacy, and safety of nasal saline irrigation.

Results: Nasal saline irrigation has often been used as both a solo and an adjunctive treatment in sinonasal diseases, including allergic rhinitis and chronic rhinosinusitis. Nasal saline irrigation has contributed to a reduction of inflammation as well as relief of nasal symptoms. Identifying the optimal technique is hampered by the fact that studies have employed various delivery devices and saline compositions, which
}

\section{Въведение}

Носните промивки (НСИ) се считат както за модерно, така и за традиционно терапевтично повлияване на синоназалните болести. Въпреки, че НСИ често се разглежда като допълнение към конвенционалното лечение на синоназалната болест, изпитванията показват, както подобрение на симптомите, така и намаляване нуждата от използване на други медикаменти (напр. кортикостероиди и антихистамини), когато се използва като моно- или в комбинираната терапия. Макар и разнообразна, голяма част от публикациите по отношение на НСИ обикновено е с ниско качество. Този преглед, цели да обобщи данните, относно механизъма на действие, ефикасността и безопасността на НСИ при пациенти със сино-назални заболявания.

\section{Епидемиология на синоназалните болестти}

Сино-назалните заболявания включват хроничния риносинуит, алергичния ринит и вирусни инфекции на горните дихателни пътища. Те съставляват значим процент от заболяванията на човешката популация. Например хроничния риносинуит (XPC) е най-честата хронична болест в САЩ при младата (до 45 години) възраст. Той засяга около $13 \%$ от населението на САЩ (1). Изследвания в САЩ относно честотата на ХРС, през 2009 г. е показала 29,3 милиона случаи, докато през 2007 г. е 12,5 милиона. Годишните разходи за лечение възлизат на близо 3 млрд. долара (2). 
subsequently have demonstrated different effects on mucus clearance, ciliary beat activity, and inflammatory mediators. Conclusion: Overall, the data appear to demonstrate clinical benefit to nasal saline irrigation. Nasal saline irrigation is well tolerated, with side effects. Further definitive studies are needed to optimize efficacy.
Медикаментозната терапия е основна терапия на ХРС и другите синоназални заболявания. Тя включва лечебни курсове с антибиотици, локални и системни стероиди, локални и перорални деконгестанти, перорални антихистамини и муколитици в краткосрочен и дългосрочен план. Хирургичното лечение е друга терапевтична възможност, показана при рефрактерни на медикаментозно лечение заболявания.

\section{История}

Произходът на носните промивки се смята, че е от древната индуска практика на Аюрведа, чиито корени се проследяват от Ведите. Те са важна част от йогийска система за прочистване на тялото. (3) Предназначени са предимно за почистване на горните въздухоносните пътища и е използвана в продължение на хиляди години, за облекчаване на синусите и алергични симптоми.

През последните години приложението на носните промивки значително нараства, поради добрите ефекти, достьпната цена и удобните форми на приложение.

\section{Механизъм на действие}

Точният механизъм на действие на НСИ не е напълно изяснен. Носният секрет постилащ лигавицата представлява една от първите бариери на тялото за защита срещу патогенни микроорганизми (7). НСИ подобряват мукоцилиарния клирьнс, имат пряко почистващо деиствие върху носната лигавица, (8) и разводняват носните секрети (9) и (10). Счита се, че повишават клирънса на медиаторите на възпалението (хистамин и простагландини), (11) предотвратяват развитието на вторична инфекция, и скъсяват периода на възстановяване на лигавицата в следствие на възпалението (9) и (10). НСИ се смята, че играят важна роля в следоперативния период, защото намаляват риска от сраствания и подобряват проходимостта в остео-меаталния комплекс (12). Поради тези причини, физиологичните промени, които теоретично се случват при използването на НСИ ги правят подходящи в терапията на много синоназални заболявания.

\section{Показания}

НСИ се препоръчват при: алергичен ринит (АР), атрофичен ринит, ринит на бременността, вирусни инфекции на горните дихателни пътища (ОКГДП), 
ХРС, остьр риносинуит, сино-назална саркоидоза, грануломатоза на Вегенер и постоперативно след функционална ендоскопска синус хирургия (10). Въпреки, че има много малко абсолютни противопоказания за НСИ, при пациенти с ненапълно излекувани травми на лицето, такива страдащите от нервно-мускулни заболявания, свързани с повишен риск от аспирация следва да избягва тази форма на лечение (13).

\section{Ефикасност}

В литературата съществуват сравнително малко на брой проучвания относно ефикасността на НСИ.

\section{Риносинуит}

Rabago et (14) изследват ефекта на НСИ при 76 възрастни с хроничен риносинуит или рецидивиращ остьр риносинуит. В това рандомизирано контролирано проучване, 52 лица са получили 150 мл на носна половина дневно по 2,0\% буфериран физиологичен разтвор, доставени чрез SinuCleanse в продължение на 6 месеца. Двадесет и четири пациенти, съставяващи контролната група не са третирани локално. Основните резултати са обективизиране чрез поълване на въпросници за качеството на живот (КЖ) и въпросници за тежестта на синоназалните симптоми (15). На 6 месеца, подобрението е $41 \%(-1,6 ; P<0.05)$ в групата с активно лечение, в сравнение с контролната група. Пациентите на активно лечение след по-малко от две седмици от лечението използват по-малко антибиотици ( $<$ 0.05) (14). При 12-месечно проследяване на това проучване, изследователите установяват трайно подобрение и значима статистическа разлика между групите $(P<0.001)(17)$.

Heatley и др. (18) сравнява ефикасността на НСИ при пациенти с ХРС. В това крьстосано проучване, 150 възрастни пациенти с ХРС били рандомизирани да получават 2,7\% хипертоничен НСИ чрез различни методи на апликация на разтвора за период от 2 седмици. Оценката се прави на база на попълване на въпросници за качеството на живот и тежестта на синоназалните симптоми. Резултатите показват, че при всички групи независимо от начина на апликация на разтвора след 2 38 седмично лечение е налице значимо подобрение и в $35 \%$ от случаите е отчетено намалена нужда от приложение на антибиотици. Недостатьк на проучването е краткото проследяване на ефекта (само 2 седмици).

In a Cochrane meta-analysis на Harvey et al, (21) авторите установили, че НСИ са ефективни при лечение на ХРС и могат да бъдат прилагани както, като монотерапия, така и в комбинация с други средства при ХРС. В този метаанализ са включени 8 проучвания отговарящи на критериите за включване. Две от проучвания сравняват ефекта на различни хипертонични разтвори в сравнение с изотоничен физиологичен разтвор. От тези проучвания могат да се направят следните изводи: НСИ са ефективни в лечението на ХРС, както като моно, така и в комбинация с други средства. Хипертоничните разтвори показват по добър ефект от изотоничните. Ефекта на НСИ е по слаб в сравнение с този на носните стероиди (21).

\section{Алергичен ринит}

Garavellos и сътр. (22) изследва ефикасността на НСИ с хипертоничен физиологичен разтвор, като допълващо лечение в предотвратяване на сезонен алергичен ринит (САР), свързани със симптомите при деца. Изследвани са 20 деца с САР (23) са рандомизирани да получават ежедневно НСИ с хипертонична $3 \%$ разтвор, аплициран със спринцовка с обем 2,5 мл във всяка ноздра три пьти на ден по време на сезона (6 седмици). Ефекта се оценява въ3 основа на попълване на въпросници за оценка на симптомите (сърбеж, ринорея, запушване на носа) ежедневно. Интензивност на всеки един от тези симптоми е оценен по скала от 0 до 4. Проучването установява значително подобрение на симптомите в 3-та , 4-та и 5-та седмица от лечението $(\mathrm{P}<0.05)$ в сравнение с контролната група. Освен това, е отчетен значителен спад в нуждата за прием на орален антихистамин $(\mathrm{P}<$ $0.05)$ по време на 3-та , 4-та и 6-та седмица от лечението. Нито един пациент не е прекъснал лечението и не е отпаднал от клиничното изпитване (22).

Друго проучване на Garavello и сьтр. (24) оценява ефекта на локалното приложение на 3\% хипертоничен физиологичен разтвор аплицирано чрез назален спрей при деца с риноконюнкт. Включени са 44 деца (< 16-годишна възраст) 
със САР получаващи хипертоничен физиологичен разтвор и контролна група без лечение в продължение на 7 седмици. Използването на антихистамин е разрешено при нужда. Оценка на ефекта се прави на базата на въпросници, поъплващи се ежеседмично, оценяващи тежестта на четири основни симптома: (1) назален секрет (2) назална обструкция (3) зачервяване на очите и (4) сърбеж в очите. Степента на тежестта на всеки симптом е записано на скала от 0 до 3 [0= няма; $1=$ леко, $2=$ умерена; $3=$ тежко. Резултатите показват подобрение през целия поленов сезон в групата с НСИ и тази разлика е статистически значимо в 6 -та и 7та седмица $(\mathrm{P}<0.05)$. Статистически значимо намаляване на приема на орален антихистамин е установено в 5 седмица $(\mathrm{P}<0.05)$. Четирима пациенти (по два от всяка група) не завършват проучването (24).

\section{Остри вирусни инфекции на горните диха- телни пътища}

Slapak et all. проучват ефектите на изотоничните носни промивки при 410 деца (6-10 г.) с остри катари на горните дихателни пътища. Te са проследени в продължение на 3 седмици по време на острата фаза на болестта (апликации от 6 пьти на ден) и още 9 седмици по време на превантивната фаза (с апликации на НСИ три пьти на ден). Ефективността се оценява чрез промяна на симптомите по време на остро заболяване (посещения 1 и 2) и през превантивната фаза (посещения 3 и 4), повторната поява на симптомите, използване на други медикаменти, усложнения, дни отсъствие от училище и обща продължителност на заболяването. Параметрите оценяват характера и вида на носната секреция, назалната конгестия, болките в гърлото, кашлицата, кихането, сърбежа и нарушенията във вкуса и обонянието. Резултатите показват статистически значимо подобрение в назалните секрети и носната конгестия в групите с НСИ в сравнение с контролната $(P<0,05)$. По време на ,превантивната фаза“, отново значително подобрение на симптомите на възпалено гърло, кашлица, назална обструкция и секреция в групата с НСИ $(P<0,05)(25)$.

Проучване на Adam et all. (26) при 143 възрастни с вирусни инфекции на горните дихателни пътища рандомизирани в три групи:
1. С хипертонична $2 \%$ буфериран спрей НСИ.

2. С физиологичен разтвор $(0,9 \%)$ НСИ.

3. Контролна (без лечение).

Основните резултати са оценка на симптомите (НСC) на 3-тия ден и обратно развитие на болестта. Резултатите от проведеното изпитване посочват, че липсват статистически значими разлики по отношение на тежестта симптомите в изследваните групи (26).

In a Cochrane meta-analysis, Kassel et al. (27) оценяващ ефикасността на НСИ при лечение на симптомите на остри катари на горните дихателни пътища при деца и възрастни. Включени са 618 участници, при които се сравнява ефекта от носните промивки с физиологичен разтвор в сравнение с други форми на лечение при възрастни и деца с клинично диагностицирани остри респираторни инфекции. Повечето резултати не показват значима разлика по отношение на ефекта между отделните наблюдавани групи. Налични са ограничени доказателства за ползата на НСИ при възрастни. Едно изследване показва намаление на симптомите с 0,3 дни (8 дни) в сравнение с контролната група. Авторите заключават, че включените проучвания са твърде малки и съществува твърде висок риск от изкривяване, за да бъдат сигурни, относно ползите от НСИ при острите катари на горните дихателни пътища.

\section{Дискусия}

От направения преглед на литературата относно ефективността на носните промивки в терапията на синоназалните болести се откриха малко на брой проучвания. Повечето включват незначителен брой пациенти и кратки срокове на наблюдение. Оценката на ефикасността е базирана основно на субективни методи вкл. въпросници за качеството на живот и тежестта на симптомите. Направени са изпитвания за ефикасността на НСИ по отношение на най-честите синоназални болести (алергичен ринит, хроничен риносинуит и остри вирусни респираторни инфекции). Използвани са основно хипертонични разтвори за приложение, като апликацията на последните е чрез различни методики. От направения преглед съществуват красноречиви доказателства 
относно положителната роля на НСИ при лечението на хроничния риносинуит, алергичния ринит и острите катри на горните дихателни пътища. Прави впечатление продължителното приложение на последните, както при острите, така и при хроничните заболявания. Средна кратност на приема трикратно при хронични и до шесткратно приложение при остри синоназални заболявания.

\section{Заключение}

НСИ често е компонент в лечение на синоназалните заболяване и обикновено се понася добре. Като цяло данните показват, клинична полза от приложението им. Изненадващ е факта, че въпреки приложението на НСИ още от древните йоги, данните за подкрепа на употребата им, към момента са минални. Публикуваните към момента клинични изпитвания посочват положителната роля на НСИ в терапията както на хроничните, така и на острите синоназални заболявания. Сравнителните данни относно ефективността на хипертоничните към изоточните разтвори по отношение на симптомите и мукоцилиарния клирънс изследван чрез захаринов тест, показ- ва превес на хипертоничния пред изотоничния. Освен това основния процент от клиничните изпитвания са проведени с хипертоничен разтвор, което допълнително подкрепя тезата за превеса му над изотоничния. За постигане на оптимален ефект е нужно продължителното приложение на НСИ. Проучванията сочат до 6-12 месеца при хроничния риносинуит и до 6-7 седмици при алергичния ринит и до 3 седмици при ОКГДП. Кратността на приема е също определящ компонент за добрата ефективност. От направения обзор може да се заключи, че оптималния прием при хроничните синоназални болести, както и за превенция на остри рецидиви е трикратен, а при острите до 6 пъти дневно. Необходими са по задълбочени проучвания относно ефикасност на носните промивки при отделните нозологични единици. Становището на Европейската асоциация по ринология за диагностика и лечение на риносинуита и носната полипоза (EPOS 2012) препоръчва използването на носните промивки в комплексното лечение на острия и хроничен риносинуит, както и след FESS [28].

\section{Литература}

1. Sinus Conditions-Faststats. National Center for Health Statistics 2010 [cited [November 2, 2011]; Available at http://www.cdc.gov/ nchs/fastats/sinuses.htm.

2. Murr A. Treatment options for chronic sinusitis. 2009 [cited 5 October, 2011]; Available at: http://www.ucsfhealth.org/newsletters/primary_care_connections/october_2009/sinus/index.html.

3. Math S. Yoga Magazine. Neti-Nasal Cleaning. 1991 [cited February 1, 2012]; Available at http://www.yogamag.net/archives/1991/ cmay91/neti.shtml.

4. Aubrey A. Got a runny nose? Flush it out! National Public Radio (NPR); 2007.

5. Neighmond P. Nasal irrigation makes comeback as cold remedy. National Public Radio (NPR), 2005.

6. Napoli M. Sinusitis: Saline irrigation works. 2007 [cited May 4 2011]; Available at http://medicalconsumers.org/2007/09/01/sinusitis-saline-irrigationworks/.

7. Brown CL, Graham SM. Nasal irrigations: good or bad? Curr Opin Otolaryngol Head Neck Surg. 2004; 12: 9-13.

8. Kurtaran H, Karadag A, Catal F, Avci Z. A reappraisal of nasal saline solution use in chronic sinusitis. Chest. 2003; 124(5): 20362037; author reply 7-8.

9. Homer JJ, Dowley AC, Condon L, El-Jassar P, Sood S. The effect of hypertonicity on nasal mucociliary clearance. Clin Otolaryngol Allied Sci. 2000; 20; 25: 558- 560.

10. Rabago D, Zgierska A. Saline nasal irrigation for upper respiratory conditions. Am Fam Physician. 2009; 80: 1117-1119.
11. Georgitis JW. Nasal hyperthermia and simple irrigation for perennial rhinitis. Changes in inflammatory mediators. Chest. 1994; 106 : 1487-1492.

12. Talbot AR, Herr TM, Parsons DS. Mucociliary clearance and buffered hypertonic saline solution. Laryngoscope. 1997; 107: 500503.

13. Barclay L. Use of saline nasal irrigation reviewed. Medscape [serial on the Internet]. 2009: Available at http://www.medscape. com/viewarticle/713108.

14. Rabago D, Zgierska A, Mundt M, Barrett B, Bobula J, Maberry R. Efficacy of daily hypertonic saline nasal irrigation among patients with sinusitis: a randomized controlled trial. J Fam Pract. 2002; 51: 1049-1055.

15. Ware J, Jr., Kosinski M, Keller SD. A 12-item short-form health survey: construction of scales and preliminary tests of reliability and validity. Med Care. 1996; 34: 220-233.

16. Benninger MS, Senior BA. The development of the Rhinosinusitis Disability Index. Arch Otolaryngol Head Neck Surg. 1997; 123: 1175-1179.

17. Rabago D, Pasic T, Zgierska A, Mundt M, Barrett B, Maberry R. The efficacy of hypertonic saline nasal irrigation for chronic sinonasal symptoms. Otolaryngol Head Neck Surg. 2005; 133: 3-8.

18. Heatley DG, McConnell KE, Kille TL, Leverson GE. Nasal irrigation for the alleviation of sinonasal symptoms. Otolaryngol Head Neck Surg. 2001; 125: 44-48.

19. Ware JE, Jr., Sherbourne CD. The MOS 36-item short-form health 
survey (SF- 36). I. Conceptual framework and item selection. Med Care. 1992; 30: 473-483.

20. Piccirillo JF, Edwards D, Haiduk A, Yonan C, Thawley SE. Psychometric and clinimetric validity of the 31-item rhinosinusitis outcome measure (RSOM- 31). Am J Rhinol. 1995; 9: 297-306.

21. Harvey R, Hannan SA, Badia L, Scadding G. Nasal saline irrigations for the symptoms of chronic rhinosinusitis. Cochrane Database Syst Rev. 2007: CD006394.

22. Garavello W, Romagnoli M, Sordo L, Gaini RM, Di Berardino C, Angrisano A. Hypersaline nasal irrigation in children with symptomatic seasonal allergic rhinitis: a randomized study. Pediatr Allergy Immunol. 2003; 14: 140-143.

23. D'Amato G, Spieksma FT, Liccardi G, et al. Pollen-related allergy in Europe. Allergy. 1998; 53: 567-578.
24. Garavello W, Di Berardino F, Romagnoli M, Sambataro G, Gaini RM. Nasal rinsing with hypertonic solution: an adjunctive treatment for pediatric seasonal allergic rhinoconjunctivitis. Int Arch Allergy Immunol. 2005; 137: 310-314.

25. Slapak I, Skoupa J, Strnad P, Hornik P. Efficacy of isotonic nasal wash (seawater) in the treatment and prevention of rhinitis in children. Arch Otolaryngol Head Neck Surg. 2008; 134: 67-74.

26. Adam P, Stiffman M, Blake RL, Jr. A clinical trial of hypertonic saline nasal spray in subjects with the common cold or rhinosinusitis. Arch Fam Med. 1998; 7: 39-43.

27. Kassel JC, King D, Spurling GK. Saline nasal irrigation for acute upper respiratory tract infections. Cochrane Database Syst Rev. 2010: CD006821.

28. EPOS 2012 